\title{
Development of a concept for integrated ecological river assessment in Flanders, Belgium
}

\author{
Peter GOETHALS* and Niels DE PAUW \\ Laboratory of Environmental Toxicology \& Aquatic Ecology, Department of Applied Ecology and Environmental Biology, Ghent \\ University, J. Plateaustraat 22, B-9000 Gent (Belgium) \\ *e-mail corresponding author: peter.goethals@rug.ac.be
}

\begin{abstract}
Integrated river management is based on monitoring, modelling and assessment of the water cycle. Effective and efficient management is only possible when these three activities are well interconnected and concerted. The choice of appropriate, high quality monitoring techniques is probably one of the most crucial factors in the assessment of river systems. To this end, the EU has recently adopted a Water Framework Directive. Although this Directive provides the guidelines for monitoring water bodies, local governments still have a lot of freedom regarding their practical implementation. The development of a consistent monitoring and assessment strategy and methodology is therefore essential for each European country. This paper discusses different Flemish techniques for the monitoring and assessment of macro-invertebrates and fish communities in relation to water quantity and the physical, chemical, morphological and structural quality. Finally, a concept for sustainable and integrated ecological assessment and management is presented.
\end{abstract}

Key words: monitoring, biological communities, nature conservation, restoration

\section{INTRODUCTION}

The EU Water Framework Directive (EU 2000) prescribes "good status" as a target for all water bodies within a river basin. In the case of surface waters, "good status" is defined as:

- good ecological status on the basis of biological, hydro-morphological and physical-chemical characteristics;

- good chemical status, measured particularly by compliance with limits for 30 priority substances (heavy metals and xenobiotics).

To reach this "good status", each EU country has to develop an optimal management strategy. In this context the Wupperverband (Germany), responsible for the river Wupper, developed the following methodological approach (Kolisch et al. 2000):

- analysis of actual situation of the water body (its actual condition);

- definition of development targets (target condition);

- quantitative assessment of deficits;

- determination of potential measures;

- analysis and selection of conservation and/or restoration scenarios;

- implementation of measures;

- monitoring of results (feedback and control).

The effectiveness of this management methodology is mainly related to technical protocols and tools delivering the required information. In the following chapters, an analysis will be made of the actual situation in Flanders and a proposal for an integrated ecological as- sessment system presented. For this, reference is made to our experience in the Zwalm River basin.

\section{EXPERIENCE IN FLANDERS RELATED TO RIVER MONITORING AND ASSESSMENT METHODS AND TECHNIQUES}

\subsection{Monitoring techniques}

Physical-chemical measurements are generally carried out in the laboratory and based on samples taken in the river. However, for some measurements, such as $\mathrm{pH}$, conductivity and dissolved oxygen, reliable field probes are now more commonly used. Field protocols for physical impact monitoring and qualitative cause allocation in Flanders were developed by Wils et al. (1994) and Schneiders et al. (1999). Basically three sampling techniques are used in Flanders to collect macroinvertebrates: kick sampling using a hand net (Fig. 1), in situ exposure of artificial substrates (Fig. 2), and benthic macroinvertebrate collection with a Van Veen grab sampler (De Pauw \& Vanhooren 1983; De Pauw et al. 1992; De Pauw \& Heylen 2001). Fish population monitoring is mainly based on electro-fishing, but netting is sometimes employed in deep rivers (Belpaire et al. 2000).

\subsection{River water quality assessment methodologies}

Water quality assessment is based either on compliance monitoring related to specific water uses (mainly applied to physical-chemical water quality assessment) or on the basis of index or score systems. To facilitate the comparison and interpretation of these index or 
score systems, they were all translated into five river quality classes, graphically presented by a colour code: blue $=$ natural; green $=$ good; yellow $=$ moderate; orange $=$ poor; red $=$ very poor.
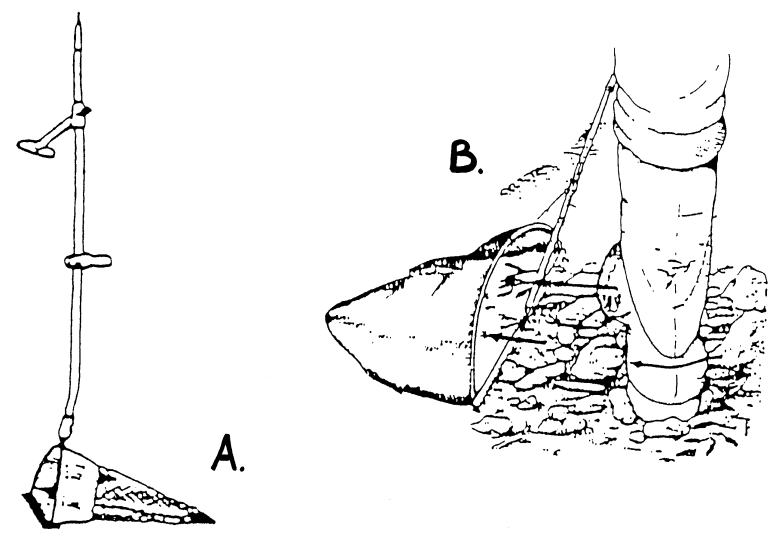

Fig. 1. Illustrations concerning the kick sampling technique by means of a hand net to collect macroinvertebrates: $\mathbf{A}$. hand net with handles; B. kick method. cently been adopted by the Flemish Environmental Agency (VMM) (De Cooman et al. 1999). This method combines physical-chemical and biological as well as ecotoxicological assessments. During recent years an Index of Biotic Integrity, based on the concept of (Karr 1981), has also been developed and validated in Flanders (Belpaire et al. 2000). An overview and brief description of the river quality assessment methods currently used in Flanders is given below.

In Flanders, the physical-chemical monitoring network consists of about 3000 measurement sites (VMM 2000). Not all measurement sites are however monitored on a yearly basis. In 1999, for instance, 1176 sites were examined (VMM 2000). On all sites a basic set of variables is monitored: water temperature, dissolved oxygen concentration, $\mathrm{pH}$, chemical oxygen demand (COD), ammonium, nitrite, nitrate, ortho-phosphate, total phosphorus, chlorides and conductivity. On a selected set of sites, biochemical oxygen demand (BOD), Kjeldahl nitrogen, sulphates, total hardness, suspended solids and heavy metals ( $\mathrm{As}, \mathrm{Cd}, \mathrm{Cr}, \mathrm{Cu}, \mathrm{Hg}, \mathrm{Pb}, \mathrm{Ni}$, $\mathrm{Zn}$ ) are also determined. In addition, discharged (treated
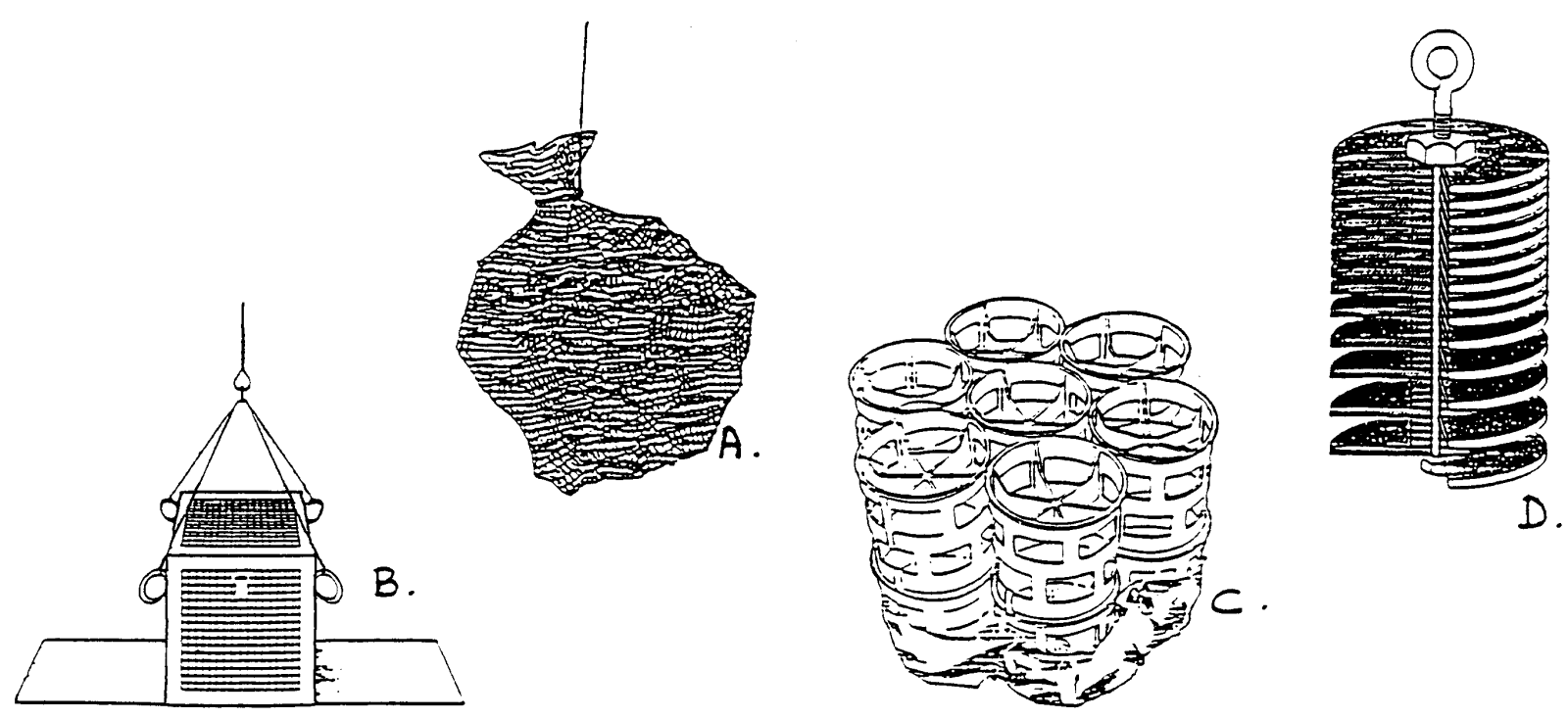

Fig. 2. Different types of artificial substrates to collect macroinvertebrates: A. Belgian variant of the standard colonisation bag; B. Dutch variant; C. standard colonisation unit; D. multi-plate Hester-Dendy sampler.

Due to increasing insight into the functions and relations in river ecosystems, these indicators are growing in complexity, and attempts are being made to assess the river quality from a holistic point of view. Monometrical systems such as saprobic and biodiversity indices have been quickly combined in multimetrical systems such as biotic indices. This trend towards integration is further emphasized in the recently adopted European Water Framework Directive (EU 2000). In Flanders, a TRIAD assessment approach for river sediments has re- as well as untreated) effluents are monitored. All these wastewaters, treated effluents and surface waters are then compared with standards as described in VLAREM II (VLAREM 1999), in which limits for the major compounds are defined for all categories of effluents and surface waters.

Prati indexes (Prati et al. 1971) are nowadays used merely for dissolved oxygen (PIO) in Flanders (De Pauw et al. 1999). This index system facilitates the interpretation of the measurement data via a formula that 
results in an index. The classes can also be converted into a colour code: $>8=$ heavily polluted or red; 4 to $8=$ polluted or orange; $2-4=$ moderately polluted or yellow; 1 to $2=$ acceptable or green; 0 to $1=$ unpolluted or blue.

Assessment of the structural characteristics of Flemish rivers is based on the structural and morphological river quality index (Wils et al. 1994). This assessment takes into account three characteristics that can be easily observed in the field: meandering capacity (or sinuosity), development of pools and riffles, and presence of natural shelters (cavities in banks). Each of these three characteristics can be given score between 2 (when the characteristic is absent and cannot be regenerated due to structural changes) and +2 (when the characteristic is natural). The overall score for the channel morphology evaluation in each location visited is calculated by adding the scores of the three characteristics. This results in a final score of between -6 and +6 . This score system can also be adapted to the five river quality classes: -6 to $-4=$ very poor or red; -3 to $-1=$ poor or orange; 0 to $+2=$ moderate or yellow; +3 to +4 $=$ good or green; +5 to $+6=$ natural or blue.

The Belgian Biotic Index (BBI) was developed as a management tool providing an insight into the biological condition of water courses in Flanders (De Pauw \& Vanhooren 1983; De Pauw \& Vannevel 1993). The methodology was standardized (NBN 1984) to facilitate its application throughout the whole of Belgium. The BBI method uses macroinvertebrates as indicators for the level of pollution. The method is based on the theorem that increasing pollution will result in a loss of diversity and a progressive elimination of certain pollution-sensitive groups. The BBI-system translates as follows: $1-2=$ very heavily polluted or red, $3-4=$ heavily polluted or orange, $5-6=$ moderately polluted or yellow, $7-8=$ slightly polluted or green, $9-10=$ unpolluted or blue.

In the TRIAD methodology, three categories of data are linked: observations demonstrating effects occurring in the field (biological data), results of bioassays linking field effects to sediment toxicity (eco-toxicological data), and concentrations of contaminants in the sediment (physical-chemical data) (De Cooman et al. 1999). The Biotic Sediment Index (BSI) (De Pauw \& Heylen 2001) and the percentage mentum deformities in Chironomus (Diptera, Chironomidae) (Heylen \& De Pauw 2001) are used as indices for biological sediment quality assessment. Eco-toxicological assessment is based on laboratory assays on the solid phase (tests with Hyalella azteca and Corophium volutator) and pore water samples (tests with Raphidocelis subcapitata and Thamnocephalus platyurus) (Vangheluwe et al. 2000). Physicalchemical assessment is based on granulometric measurements, percentage organic matter, heavy metal content (As, $\mathrm{Cd}, \mathrm{Cr}, \mathrm{Cu}, \mathrm{Hg}, \mathrm{Pb}, \mathrm{Ni}, \mathrm{Zn}$ ) and some organic micro-pollutants such as poly-aromatic hydrocarbons (PAHs), pesticides, ... (de Deckere et al. 2000) Finally, all measurements are combined in three separate score systems for physico-chemistry, eco-toxicology and biology, resulting in a colour class for each group of measurements (de Deckere et al. 2000).

The Fish Index or Index of Biotic Integrity (IBI) (Belpaire et al. 2000) is still being developed for Flemish watercourses. The index is based on a set of indices for five water typologies, according to those defined by M. Huet (Vandelannoote et al. 1998): the trout zone, grayling zone, barbel zone, carp zone and brackish water zone. Each index is based on three groups of variables: species composition, trophic composition and fish condition. The IBI integrates the characteristics of a population and the individual species in one number, which also results in a colour class.

Research is also currently being done on assessment methods based on diatoms and macrophytes (Triest et al. 2001). These ecosystem components will also be assessed on the basis of an index.

\subsection{The Zwalm River basin}

The Zwalm River basin is part of the Scheldt river basin (Carchon \& De Pauw 1997). The Zwalm River basin has a total surface of 11,650 ha, and the Zwalm River is $22 \mathrm{~km}$ long (Fig. 3). The average water flow (at Nederzwalm, very near the Scheldt) is about one $\mathrm{m}^{3} \mathrm{~s}^{-1}$. It has a very irregular regime, with low values in the summer (minima lower than $0.3 \mathrm{~m}^{3} \mathrm{~s}^{-1}$ ) and relatively high values in rainy periods (maximums up to $4.7 \mathrm{~m}^{3}$ $\mathrm{s}^{-1}$ ) (Lauryssen et al. 1994). The water quality in the Zwalm River basin improved greatly during the year 1999 , due to investments in sewer systems and wastewater treatment plants during the last few years (VMM 2000). Nevertheless, most parts of the river are still polluted by untreated urban wastewater discharges and by diffuse pollution originating from agricultural activities. Although Flanders is in general rather flat, the Zwalm River basin is characterized by a number of differences in altitude, making it a quite unique river ecosystem within the Flemish Region (Soresma 2000). Consequently, soil erosion is the most important geomorphological process and results in an important transport of (contaminated) sediments into the river (AMINAL 1999). There are also numerous structural and morphological disturbances (Carchon \& De Pauw 1997). Weirs for water quantity control obstruct fish migration and are one of the most important ecological problems in the river basin. An in-depth study has therefore been made on the development of fish migration channels and natural overflow systems, with a view to reaching ecologically friendly water quantity management in the near future (Soresma 2000). Some of the upper reaches of the watercourses in the Zwalm River basin are colonized by very rare species such as Bullhead (Cottus gobio), Brook Lamprey (Lampetra planeri) and several vulnerable macroinvertebrates. 


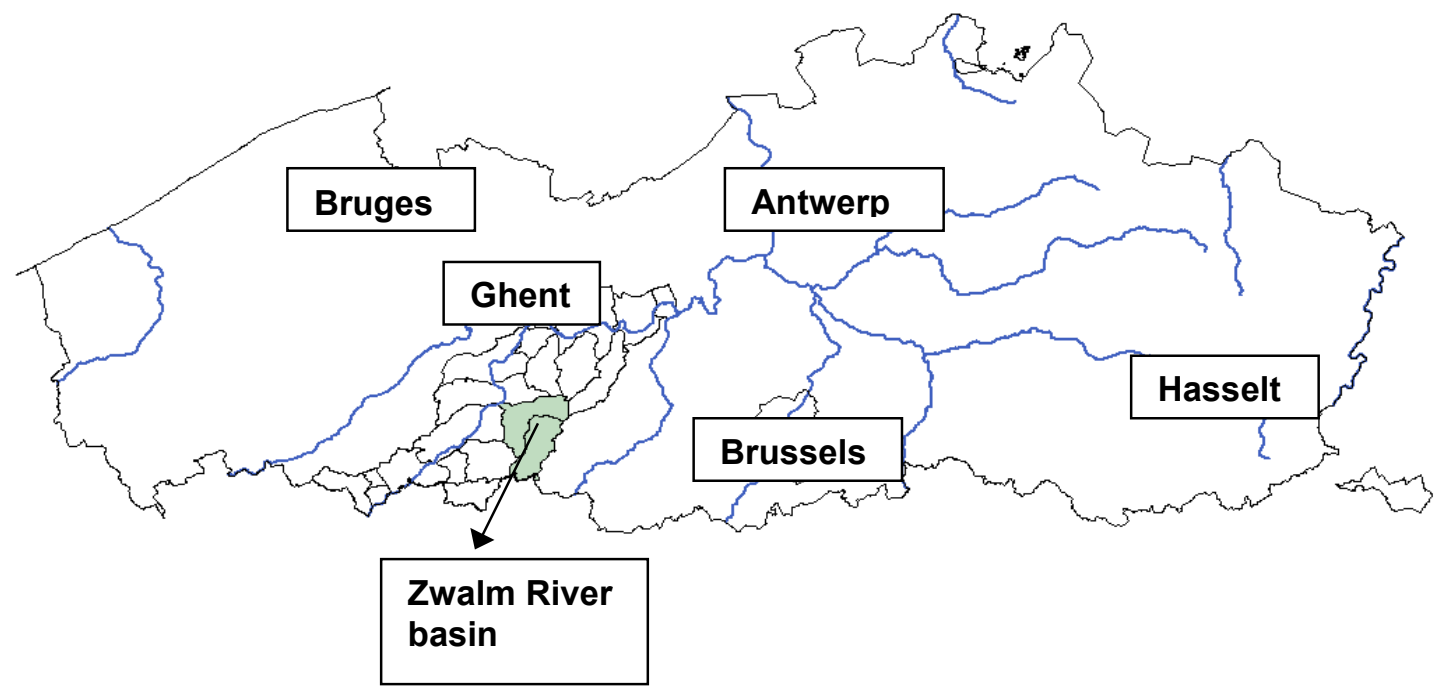

Fig. 3. The Zwalm River basin in Flanders (Belgium).

\section{DEVELOPMENT OF AN INTEGRATED ECOLOGICAL ASSESSMENT SYSTEM FOR NATURE CONSERVATION AND RESTORATION IN RIVER BASINS}

\subsection{A multidisciplinary analysis of the river ecosystem}

Before a reasoned choice of a set of restoration and/or conservation methods can be made, a multidisciplinary analysis should be carried out. In particular, this involves an environmental analysis aimed at preserving the area's fauna and flora and at restoring its former ecological diversity (Belleudy 2000), obviously taking account of the general socio-economical functions of that catchment. Qualitative concepts (Fig. 4) of interactions between ecological variables are numerous; examples can be found in De Pauw \& Hawkes (1993), Braukmann \& Pinter (1997) and Lafont et al. (2001). A more profound integrated ecological assessment concept was recently established by Verdonschot (2000), based on the 5-S-Model (Verdonschot et al. 1998). This model aims at allowing river managers to make proper choices based on a sound understanding of the functioning and interaction of the controlling factors. All considerations of concepts, scales and hierarchies provide a conceptual basis for "catchment ecology". The five main components of the model are (Verdonschot et al. 1998).

1. "System conditions": the structures and processes related to climate (temperature, rain-fall), geology and geomorphology (slope, soil composition), which set the boundary conditions for stream ecosystem functioning at a high hierarchical level in space (the catchment) as well as in time ( \pm 100 years). Generally, system conditions are not often changed by management.

2. "Stream hydrology": the hydrological processes of the catchment and the hydraulic processes of the stream and the habitat (Henry \& Amoros, 1995). The two main directions of flow are one running from the boundary of the catchment towards the stream (lateral) and one running from source to mouth of the stream (longitudinal). Groundwater flow, precipitation and evaporation also play a role.

3. "Structures": the morphological features of the longitudinal and transversal stream bottom, banks and beds, as well as the substrate patterns within them. The cut of meanders, terrestrialization, sand deposits and other features of the stream valley are included here.

4. "Substances": the processes related to dissolved components like nutrients, organic matter, oxygen, major ions and contaminants. From the catchment boundary towards the stream, the amount of dissolved substances increases. This increase is also visible from source to mouth.

5. "Species": the response to the functioning of all the above groups of controlling factors. "Species" includes all taxonomic and non-taxonomic entities, as well as biotic processes like production, respiration and so on. Species and their communities are the actual goal of ecological stream management and rehabilitation.

The five components mutually interact at different hierarchical levels and with different intensities. In general, however, stream hydrology, structures and substances together compose the group of controlling factors that directly determine how the stream community functions. Nevertheless, numerous exceptions to this rule exist, e.g. species can adapt to stream hydrology and at the same time (e.g. trees) can impact stream hydrology and morphology. Thus, despite a dominant hierarchical effect, a feedback is always present. Knowledge of the hierarchy in factors and processes allows us also to infer the direction and magnitude of potential 


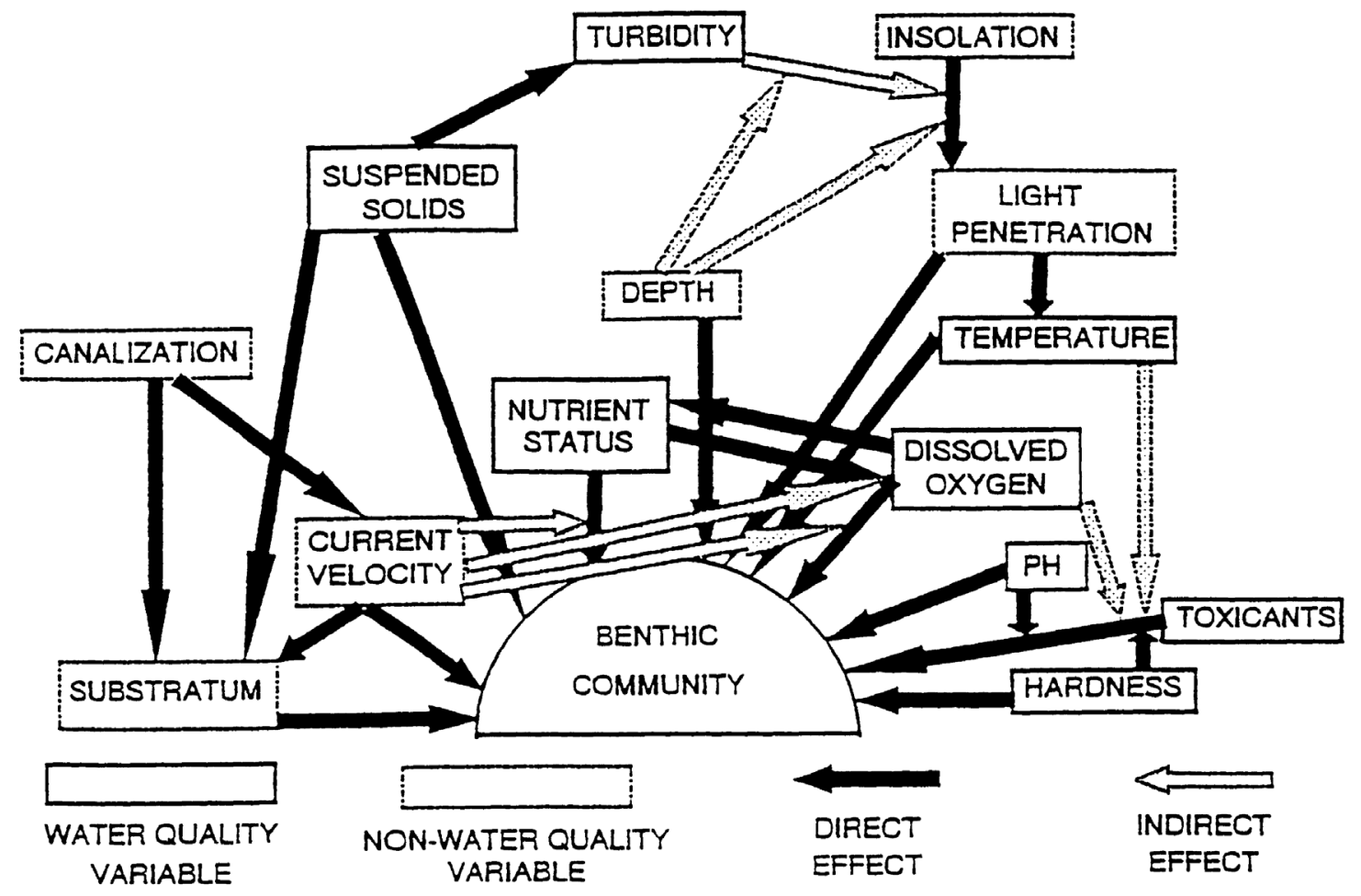

Fig. 4. Qualitative river ecosystem concept as described by De Pauw \& Hawkes (1993).

changes due to human activities (Naiman et al. 1992). Human disturbances can be seen as the sixth "S", that of "Steering". Steering is not separately distinguished in the model but is part of all five other Ss. The disturbance and restoration of streams is steered in a negative or positive direction. However, for an efficient and effective integrated ecological assessment, it is necessary to have insight into both the natural river dynamics and human disturbances. A reliable cause-effect assessment as well as the prediction of restoration effects is also very important in river basin management.

Many problems are related to the spatial planning of activities. In particular, where dwellings are located far apart, the sanitation of wastewater is very expensive and inefficient. In addition, other problems such as "accidents" derive from social habits and are difficult to change, sometimes because of inappropriate legislative tools.

\subsection{Applications of models in the development of integrated ecological assessment methods}

Interest in modelling as a powerful tool to support river quality assessment has arisen only recently. The "River Invertebrate Prediction and Classification System" (RIVPACS) was one of the first and best known systems in this context (Wright et al. 1984; Wright et al.
2000). RIVPACS is based on classical statistical modelling. The science of modelling has however evolved substantially during recent years (Jorgensen 1999), and several new techniques, such as artificial neural networks (Lek \& Guegan 1999), fuzzy logic (Barros et al. 2000), evolutionary algorithms (Caldarelli et al. 1998), cellular automata (Gronewold \& Sonnenschein 1998), ... are beginning to penetrate the field of ecological modelling. Decision support systems for river quality assessment and management will probably also be looking to these techniques within a couple of years.

Until recently, rather than predicting the biology, structure, ... at a specific site, river managers preferred to use score systems based on characteristics of ecological systems. Modelling was not popular, due to imprecise and inaccurate predictions of actual and also of reference situations. On the other hand, many indices are rather subjective and have been pragmatically developed, leaving the river manager with various exceptions in his score system that he cannot explain. Models might be usefully employed to reduce the subjectivity of these score systems, to allow a better interpretation of the results, to come to a cause-allocation of the state of a river and also to increase the insight necessary to improve assessment systems (Fig. 5). The development of effective and efficient monitoring networks based on models is probably another important advantage. 

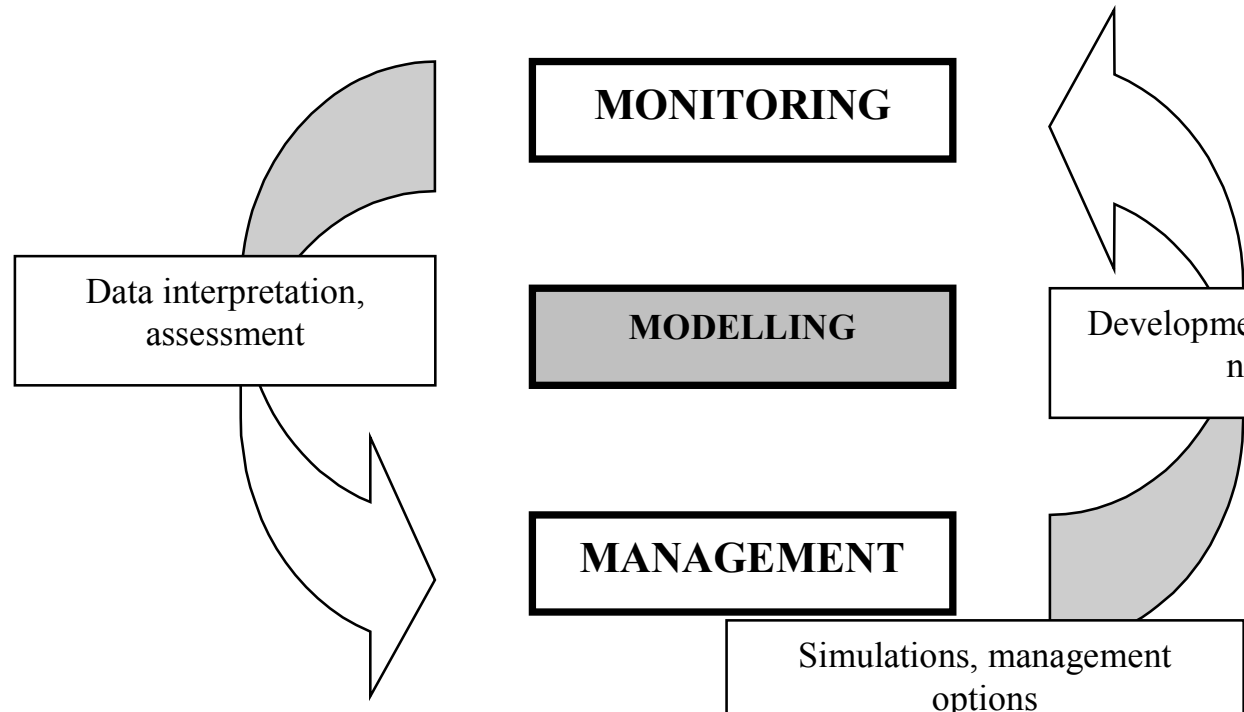

Development of monitoring networks

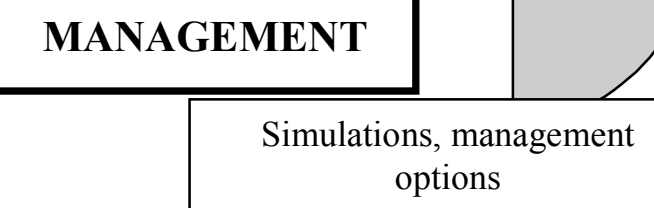

Fig. 5. Potential applications of ecosystem models in integrated river management.

Several types of models need to be established to deal with river assessment: hydrological, ecological, those related to pollution sources (sewers, wastewater treatment plants, agricultural activities, etc.), etc. But models dealing with the economic aspects of ecosystems and all other river basin activities are also necessary. Another crucial aspect of ecological models is the way they deal with the sampling methods applied. Several factors regulate sampling data: site selection (at random or biased, amount, size of the sampling site), sampled river compartments, absolute or relative species collection, sampling probabilities (quickly moving or hiding organisms), ease of sampling (e.g. a very stony site can disturb Van Veen Grab sampling; vegetation, turbid water, deep water can inhibit electrofishing, etc.), sampling technique, etc. The assessment system should of course consider these factors and avoid their being reflected in the final score.

It is obvious that models have many limitations and that often the reliability of ecological models is rather low. Nevertheless, it must be considered better to have a roughly correct prediction than no prediction at all.

\subsection{Sustainable integrated ecological management}

River management has changed from responding to past problems to detecting problems at an early stage and even predicting and preventing those likely to arise in the future (Verdonschot 2000). An increase in the scale and types of threats led to an increase in management objectives and thus in the need for more and improved assessment techniques and monitoring tools, as well as an integrated and multidisciplinary approach.

The need for an integrated approach is also becoming urgent. All the possible dimensions directly or indi- rectly influencing water management must therefore be considered, with a view to developing optimal (or at least sustainable) management solutions.

The main management dimensions are:

- "time": short term decisions should be compatible with long term decisions, and the establishment of optimal restoration or conservation should be aimed at in the long run;

- "space": decisions must take the local as well as the global objectives into consideration (e.g. optimizations for the Zwalm River basin must be compared with those for the Scheldt river basin and the North sea);

- "ecosystem components": all components of the ecosystem should be included, which means fish, algae, macrophytes, $\ldots$ besides macroinvertebrates;

- "river catchment functions": all activities must be weighted and exploitation of the river basin should be sustainable;

- "abilities": probably one of the major difficulties in Flanders, due to its complex political structure. An unequivocal implementation of the Water Framework Directive by the central administration, as well as by all agencies, parastatal organizations, ... will be necessary to avoid a fragmented and inefficient approach;

- "legislative tools": all legislative tools aimed at improving nature restoration and conservation, and which make polluters pay, should be concerted.

The multiple dimensions of integrated and sustainable river management make it difficult, and many parties and complex legislative constructions are involved. A robust, simple, user-friendly core system that allows some flexibility in its practical implementation is there- 
Tab. 1. Description of the main factors responsible for the spatial and temporal diversity in the ecosystem in the Zwalm River basin.

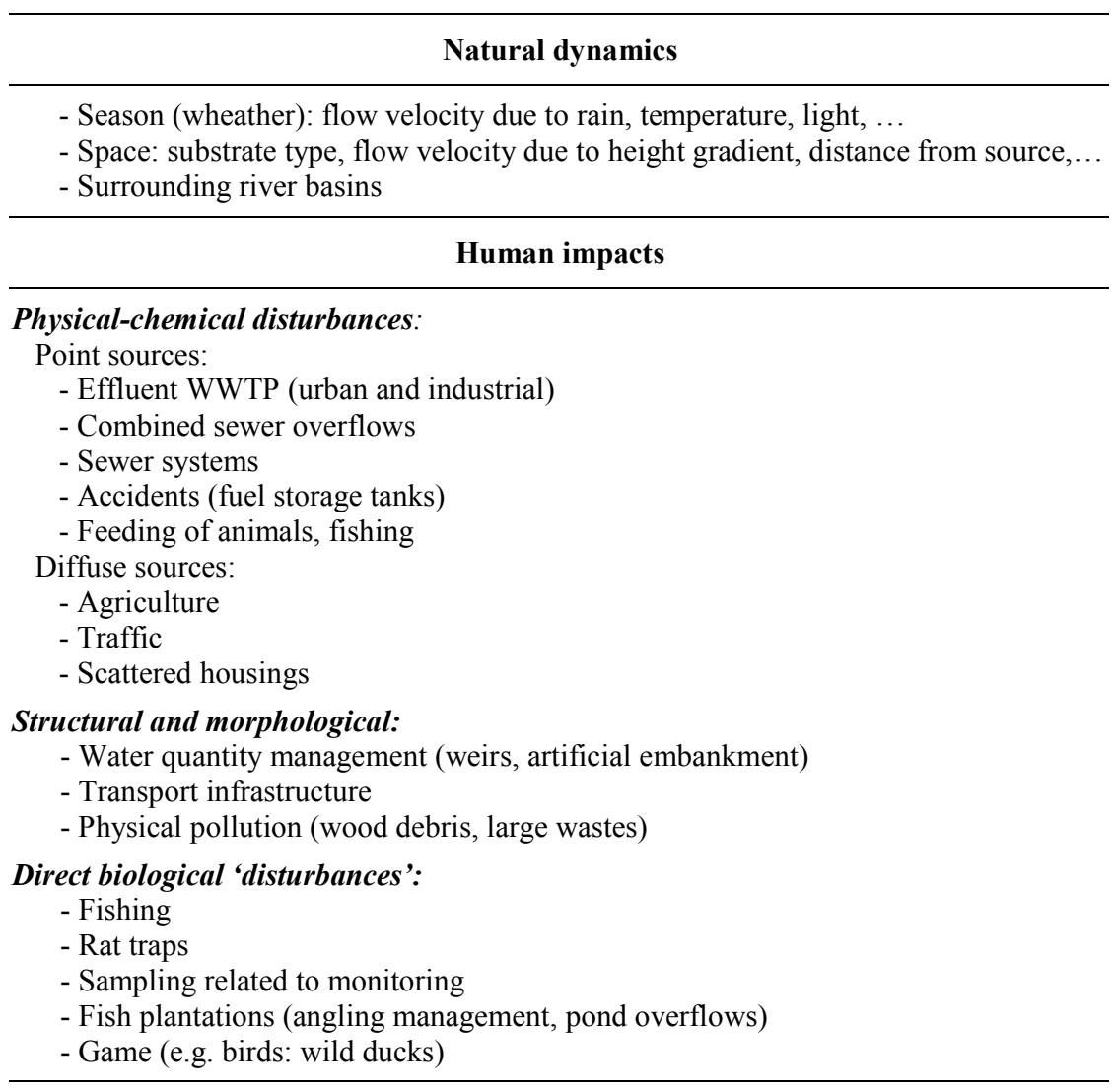

fore necessary to ensure that all the parties involved can handle it comfortably.

\subsection{Proposal for an integrated ecological river assessment system for Flanders, as exemplified by the River Zwalm}

The application of integrated ecological catchment management or the assessment of a new stream site involves several steps (for further explanation see also Verdonschot \& Nijboer (1997)).

First, differentiation into ecological region and stream and river types is an essential starting point (Verdonschot 2000). In the Zwalm catchment system, two main regions can be distinguished: the lotic stream system, consisting of very small upper reaches (with brown trout as a very typical fish species), and the Zwalm River itself, which is larger and still a fast running stream system (with grayling as a typical fish species), but including artificial lentic stretches in the vicinity of a number of weirs.

Second, stream ecosystems should be described in a catchment context, i.e., over multiple scales: the "ecological catchment approach". For the Zwalm this means that management can be focused on part of the catchment or on the whole Zwalm basin, but also as part of the basin of the Upper Scheldt or even the whole
Scheldt basin, depending on the type of problem to be tackled.

Third, each stream and river type must be defined in ranges of abiotic and biotic terms at different scales: an "ecological typology approach".

Fourth, all human activities in the catchment should be recognised and their impact on the stream/river type quantified: a "societal approach". This requires knowledge on cause-effect relationships of the natural as well as the anthropogenic factors (Tab. 1).

These four approaches bring water management and nature conservation together and offer a framework for multiple scales. The implementation of these needs requires techniques which can describe, develop, monitor, assess, evaluate and test; knowledge on cause-effect relationships; techniques which can survey, prioritise, predict, aggregate and split; techniques for trend-analysis and knowledge- and expert systems. Coherency between these tools is vital: everything should be supported by standardisation of techniques and methods, an informative presentation and well thought-out relations with the society involved.

With regard to the presentation, a geographical information system (GIS) is very important. For this reason, a Zwalm River basin database has been developed which can be implemented in a GIS. Carchon \& De 


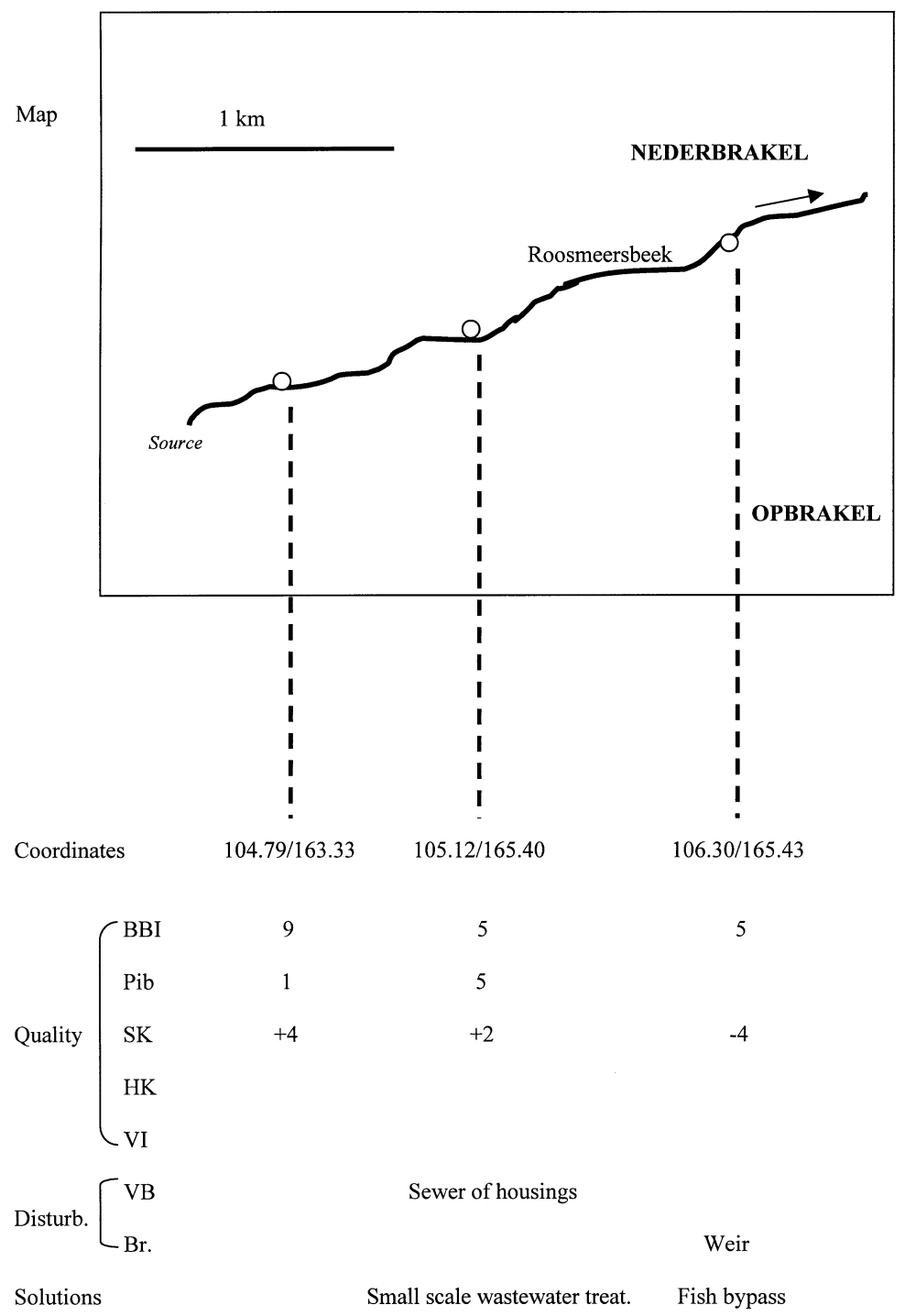

Fig. 6. Schematic representation of the integrated visualisation technique for river assessment and management in Flanders developed by Carchon \& De Pauw (1997). The map illustrates the concerning river stretch. The first set of lines is related to the coordinates of the sampling sites. The river quality lines represent the most recent data on the physical and chemical, biological and structural and morphological status of the river by means of indices (BBI $=$ Belgian Biotic Index; PIb $=$ Basic Prati-Index; $\mathbf{S K}=$ structural and morphological river quality index; HK = habitat quality index; VI = fish index or IBI). The lines of disturbances describe pollution sources (VB) and migration barriers (Br). The lowest line proposes potential solutions.

Pauw (1997) developed a methodology for facilitating the assessment of the integrated ecological status of a river. This was based on the use of charts in which coloured lines and symbols give information on ecological quality, types of disturbances, their causes and also potential solutions. The river quality lines represent the most recent data on the physical and chemical, biological, and structural and morphological status of the river. The different quality classes are shown using five colours. Two lines represent the disturbances: one for discharge locations and one for physical obstructions. The 'potential solutions' line finally indicates which problems should be tackled first. An example of a small stream in the Zwalm River basin is given in figure 6 . The methodology is being further optimised, as well as being implemented in a geographical information system.

\section{CONCLUSIONS}

Sustainable river management cannot be confined to a mere consideration of water quantity (e.g. floodings) and water quality control (which nowadays involves simply monitoring pollution loads). Migration facilities, structural river quality, and direct management of the biology must also be considered carefully within an integrated framework taking account of all the functions 
the river has to support. It follows that a multidisciplinary approach is required, and a consistent integrated concept should be further optimised.

River ecosystem models are of great interest as tools which can assist in making such decisions as setting up monitoring networks, defining and interpreting river quality assessment, and selecting river management actions.

River basin monitoring (which at the moment is merely based on physical-chemical and macroinvertebrate analyses) also needs to involve other relevant communities like fish, macrophytes, etc, to provide a complete picture of ecosystem quality. Integration of databases and development of models can in many cases make monitoring much more effective and efficient.

Integrated river assessment always involves a large amount of subjectivity. Nevertheless, all possible ways of improving objectivity should be tried. Models are probably important tools for setting up assessment systems, but also for defining the reliability of the systems and supporting our interpretation of the results. An unequivocal approach is necessary if we are to realize a comprehensive methodology that allows short-term as well as long-term assessment and decision support.

\section{REFERENCES}

AMINAL 1999. Control of sediment transport in unnavigable watercourses as part of integrated water management: Zwalm River basin project. Ghent University \& Catholic University of Leuven, Gent. (in Dutch).

Barros, L.C., R.C. Bassanezi \& P.A. Tonelli. 2000. Fuzzy modelling in population dynamics. Ecological Modelling, 128: $27-33$

Belleudy, F. 2000. Restoring flow capacity in the Loire River bed. Hydrological Processes, 14: 2331-2344.

Belpaire, C., R. Smolders, I. Vanden Auweele, D. Ercken, J. Breine, G. Van Thuyne \& F. Ollevier. 2000. An Index of Biotic Integrity characterizing fish populations and the ecological quality of Flandrian water bodies. Hydrobiologia, 434: 17-33.

Braukmann, U. \& I. Pinter. 1997. Concept for an integrated ecological evaluation of running waters. Acta Hydrochim. Hydrobiol., 25: 113-127.

Caldarelli, G., P.G. Higgs, \& A.J. McKane. 1998. Modelling coevolution in multispecies communities. Journal of Theoretical Biology, 193: 345-358.

Carchon, P. \& N. De Pauw. 1997. Development of a methodology for the assessment of surface waters. Study by order of the Flemish Environmental Agency. Ghent University, Laboratory of Environmental Toxicology and Aquatic Ecology, Gent. (in Dutch).

De Cooman, W., M. Florus, M. Vangheluwe, C. Janssen, S. Heylen, N. De Pauw, E. Rillaerts, P. Meire \& R. Verheyen. 1999. Sediment characterisation of rivers in Flanders. In: G. De Schutter (Ed.), CATS 4. PIH, Antwerp (Belgium).

de Deckere, E., W. De Cooman, M. Florus, \& M.P. DevroedeVanderlinden. 2000. Characterisation of Flemish navigable watercourses. AMINAL, Brussels. (in Dutch)

De Pauw, N. \& H.A. Hawkes. 1993. Biological monitoring of river water quality. In: W.J. Walley \& S. Judd (Eds), River water quality monitoring and control. Aston University, Birmingham: 87-111.
De Pauw, N. \& S. Heylen. 2001. Biotic index for sediment quality assessment of watercourses in Flanders, Belgium. Aquatic Ecology, 35:121-133.

De Pauw, N., V. Lambert \& A. Van Kenhove. 1992. Application of artificial substrates for biological monitoring of large rivers and canals in Flanders and The Netherlands. Flemish Environmental Agency (VMM), Erembodegem. (in Dutch)

De Pauw, N., H. Maeckelberghe, C. Belpaire, J. Breine, W. De Cooman, M. Florus, \& M. Van Steertegem. 1999. Surface water quality. In: VMM (Ed.), MIRA-T 1999: environmental and nature report of Flanders.. Garant, Erembodegem (Belgium): 313-332 (in Dutch).

De Pauw, N. \& G. Vanhooren. 1983. Method for biological quality assessment of water courses in Belgium. Hydrobiologia, 100: 153-168.

De Pauw, N. \& R. Vannevel. 1993. Dossiers Stichting Leefmilieu 11: Macroinvertebrates and water quality. Stichting Leefmilieu, Antwerp.

EU 2000. Directive of the European Parliament and of the Council 2000/60/EC establishing a framework for community action in the field of water policy. Rep. No. PECONS 3639/1/00 REV 1. European Union, Luxembourg.

Gronewold, A. \& M. Sonnenschein. 1998. Event-based modelling of ecological systems with asynchronous cellular automata. Ecological Modelling, 108: 37-52.

Henry, C.P. \& C. Amoros. 1995. Restoration ecology of riverine wetlands: I. A scientific base. Environmental Management, 19: 891-902.

Heylen, S. \& N. De Pauw. (2001). Mentum deformations in Chironomus larvae for assessment of freshwater sediments in Flanders, Belgium. Verh. int. Ver. Limnol.: (in press).

Jörgensen, S.E. 1999. State-of-the-art of ecological modelling with emphasis on development of structural dynamic models. Ecological Modelling, 120: 75-96.

Karr, J.R. 1981. Assessment of biotic integrity using fish communities. Fisheries, 6: 21-27.

Kolisch, G., J. Londong, \& J. Renner. 2000. Integrated and sustainable river basin management by German river associations. Water, 10: 38-41.

Lafont, M., J.-C. Camus, A. Fournier \& E. Sourp. (2001). A practical concept for the ecological assessment of aquatic ecosystems: application on the River Dore in France. Aquatic Ecology: (in press).

Lauryssen, F., F. Tack, \& M. Verloo. 1994. Nitrogen transport in the Zwalm River basin. Water, 75: 46-49 (in Dutch).

Lek, S. \& J.F. Guegan. 1999. Artificial neural networks as a tool in ecological modelling, an introduction. Ecological Modelling, 120: 65-73.

Naiman, R.J., D.G. Lonzarich, T.J. Beechie, \& S.C. Ralph. 1992. General principles of classification and the assessment of conservation potential in rivers. In: P.J. Boon, P. Calow \& G.E. Petts (Eds), River conservation and management. Wiley \& Sons, Chichester, UK.: 93-124.

NBN 1984. Qualité biologique des cours d'eau: détermination de l'indice biotique se basant sur les macro-invertebres aquatiques, NBN T92-402. Institut Belge de Normalisation (IBN).

Prati, L., R. Pavanello, \& F. Pesarin. 1971. Assessment of surface water quality by a single index of pollution. Water Research, 5: 741-751.

Schneiders, A., C. Wils, \& R. Verheyen. 1999. The use of ecological information in the selection of quality objectives for river conservation and restoration in Flanders (Belgium). Aquatic Ecosystem Health and Management, 2: $137-154$.

Soresma. 2000. Environmental impact assessment report on the development of fish migration channels and natural overflow systems in the Zwalm River basin. Soresma advies- en ingenieursbureau, Antwerp. (in Dutch). 
Triest, L., A. Kaur, S. Heylen \& N. De Pauw. 2001. Comparative monitoring of diatoms, macroinvertebrates and macrophytes in the Woluwe River (Brussels, Belgium). Aquatic Ecology, 35: 183-194.

Vandelannoote, A., R. Yseboodt, B. Bruylants, R. Verheyen, J. Coeck, C. Belpaire, G. Van Thuyne, B. Denayer, J. Beyens, D. De Charleroy, J. Maes, \& P. Vandenabeele. 1998. Atlas of the Flemish creek and river fish v.z.w. Water-Energik-vLario (WEL), Wijnegem. (in Dutch).

Verdonschot, P.F.M. 2000. Integrated ecological assessment methods as a basis for sustainable catchment management. Hydrobiologia, 422/423: 389-412.

Verdonschot, P.F.M., J.M.C. Driessen, H.G. Mosterdijk, \& J.A. Schot. 1998. The 5-S-Model, an integrated approach for stream rehabilitation. In: H.O. Hansen \& B.L. (Eds), Madsen River Restoration '96. European Centre for River Restoration, Denmark: 36-44

Verdonschot, P.F.M. \& R.C. Nijboer. 1997. Typology of macrofaunal assemblages applied to water and nature man- agement; a Dutch approach. In: The RIVPACS International Workshop. Oxford, Oxford, UK.

VLAREM 1999. VLAREM II. Conclusions of the Flemish Government of $01 / 06 / 95$ on general and sectoral guidelines on environmental hygiene. (in Dutch).

VMM 2000. Water quality - water discharges 1999. Flemish Environmental Agency, VMM, Erembodemgem. (in Dutch).

Wils, C., A. Schneiders, L. Bervoets, A. Nagels, L. Weiss, \& R.F. Verheyen. 1994. Assessment of the ecological value of rivers in Flanders (Belgium). Water Science and Technology, 30: 37-47.

Wright, J.F., B. Moss, P.D. Armitage, \& M.T. Furse. 1984. A preliminary classification of running-water sites in Great Britain based on macro-invertebrate species and the prediction of community type using environmental data. Freshwater Biology, 14: 221-256.

Wright, J.F., D.W. Sutcliffe \& M.T. Furse. 2000. Assessing the biological quality of fresh waters: RIVPACS and other techniques. FBA, Ambleside (UK): 373 pp. 